\title{
Sensorimotor Processing in the Newborn Rat Red Nucleus during Active Sleep
}

\author{
Carlos Del Rio-Bermudez, ${ }^{1}$ Greta Sokoloff, ${ }^{1}$ and ${ }^{\circledR}$ Mark S. Blumberg ${ }^{1,2}$ \\ ${ }^{1}$ Department of Psychology and ${ }^{2}$ Department of Biology, University of Iowa, Iowa City, Iowa 52242
}

\begin{abstract}
Sensory feedback from sleep-related myoclonic twitches is thought to drive activity-dependent development in spinal cord and brain. However, little is known about the neural pathways involved in the generation of twitches early in development. The red nucleus (RN), source of the rubrospinal tract, has been implicated in the production of phasic motor activity during active sleep in adults. Here we hypothesized that the RN is also a major source of motor output for twitching in early infancy, a period when twitching is an especially abundant motor behavior. We recorded extracellular neural activity in the RN during sleep and wakefulness in 1-week-old unanesthetized rats. Neurons in the RN fired phasically before twitching and wake movements of the contralateral forelimb. A subpopulation of neurons in the RN exhibited a significant peak of activity after forelimb movement onset, suggesting reafferent sensory processing. Consistent with this observation, manual stimulation of the forelimb evoked RN responses. Unilateral inactivation of the RN using a mixture comprising $\mathrm{GABA}_{\mathrm{A}}, \mathrm{GABA}_{\mathrm{B}}$, and glycine receptor agonists caused an immediate and temporary increase in motor activity followed by a marked and prolonged decrease in twitching and wake movements. Altogether, these data support a causal role for the RN in infant motor behavior. Furthermore, they indicate that twitching, which is characterized by discrete motor output and reafferent input, provides an opportunity for sensorimotor integration and activity-dependent development of topography within the newborn RN.
\end{abstract}

Key words: myoclonic twitching; reafference; REM sleep; sensorimotor; somatotopy; topography

\section{Introduction}

The infant nervous system must adjust rapidly to changes in the biomechanical properties of limbs within the context of a continually changing body. One important contributor to this process occurs during wakefulness as infants learn about the relationship between self-generated movements and the associated sensory feedback (i.e., reafference) arising from them (Wolpert et al., 1995; Berthier et al., 2005; Robinson et al., 2008).

But self-generated movements are not restricted to periods of wakefulness. On the contrary, twitching of the limbs during active [or rapid eye movement (REM)] sleep is among the most abundant of all newborn behaviors (Roffwarg et al., 1966; JouvetMounier et al., 1970; Blumberg and Seelke, 2010). Twitches are discrete events that occur against a background of muscle atonia, thereby facilitating high-fidelity transmission of reafference related to the biomechanical properties of limbs (Blumberg et al., 2013a). Indeed, twitch-related reafference drives neural activity in structures across the neuraxis, including the spinal cord ( $\mathrm{Pe}-$ tersson et al., 2003), thalamus (Tiriac et al., 2012), cerebellum

\footnotetext{
Received Feb. 9, 2015; revised April 20, 2015; accepted April 23, 2015

Author contributions: C.D.R.-B., G.S., and M.S.B. designed research; C.D.R.-B. performed research; C.D.R.-B. and G.S. analyzed data; C.D.R.-B. and M.S.B. wrote the paper.

This work was supported by grants from the National Institutes of Health (R37-HD081168, R01-HD063071) to M.S.B., C.D.R.-B. was supported by the Fulbright Foreign Student Program. We thank Alex Tiriac for helpful comments.

The authors declare no competing financial interests.

Correspondence should be addressed to Mark S. Blumberg at the above address. E-mail: mark-blumberg@uiowa.edu.

DOI:10.1523/JNEUROSCI.0564-15.2015

Copyright $\odot 2015$ the authors $\quad 0270-6474 / 15 / 358322-11 \$ 15.00 / 0$
}

(Sokoloff et al., 2014), hippocampus (Mohns and Blumberg, 2008), somatosensory cortex (Khazipov et al., 2004; Tiriac et al., 2012), and motor cortex (Tiriac et al., 2014). Finally, reafferent signals from twitching limbs are processed differently from those associated with wake movements, further indicating that twitches are ideally suited to contribute to activity-dependent development of the sensorimotor system (Tiriac et al., 2014).

With respect to the motor systems responsible for twitching, spinal transections (Robinson et al., 2000), decerebrations (Kreider and Blumberg, 2000), and neural recordings (Karlsson and Blumberg, 2005; Karlsson et al., 2005) in fetal and neonatal rats suggest that spinal mechanisms gradually come under the control of mesopontine circuits. The mesopontine area contains nuclei that are involved in REM sleep generation (Chase and Morales, 1990; Siegel et al., 1992; Leonard and Llinás, 1994; Boissard et al., 2002) and are presumed to produce twitching via brainstem premotor nuclei. The red nucleus (RN) is one such nucleus, having been identified in adult mice and cats as a source of twitch-related motor outflow (Gassel et al., 1966; Li and Peever, 2014). The RN is the source of the rubrospinal tract (RST; Kuypers, 1981) and plays an important role in the regulation of muscle tone (Mileykovskiy et al., 2002), skilled limb movements (Hermer-Vazquez et al., 2004; Morris et al., 2015), and overground locomotion (Muir and Whishaw, 2000). The role of the $\mathrm{RN}$ in motor control is particularly important in early infancy before corticospinal connections have fully developed (Williams et al., 2014).

In the present study, we recorded spontaneous and evoked neural activity in the RN and selectively inhibited it in week-old rats to test the hypothesis that the $\mathrm{RN}$ is involved in the genera- 
A

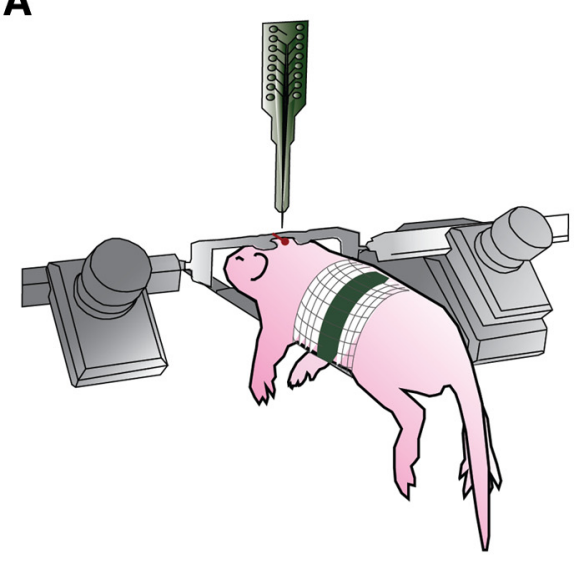

B

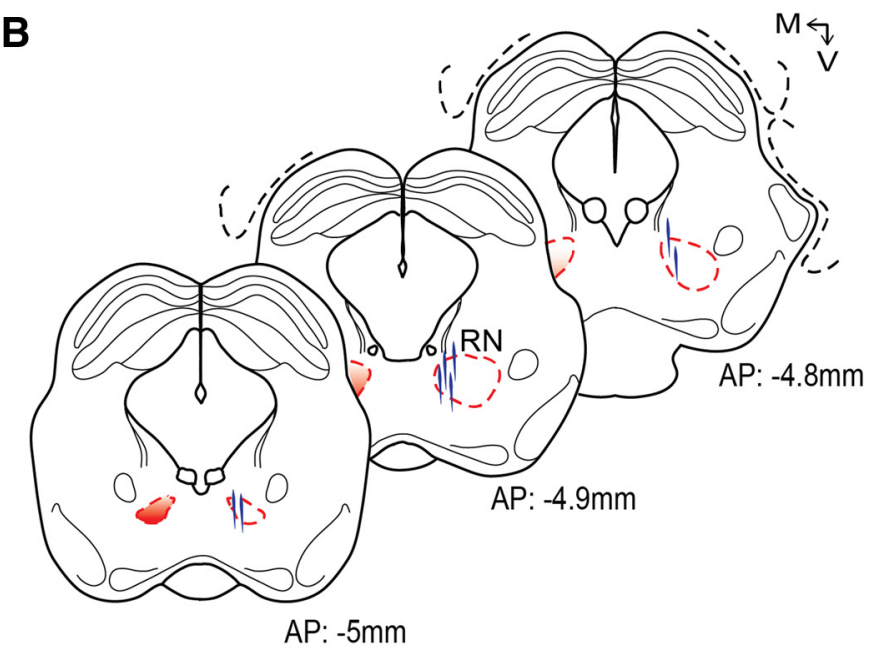

C

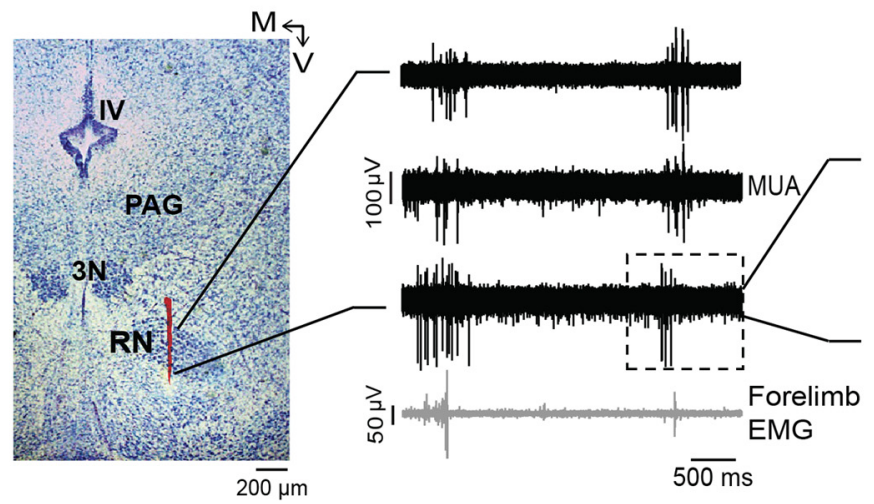

${ }^{*}$ All ISIs $\leq 8 \mathrm{~ms}$

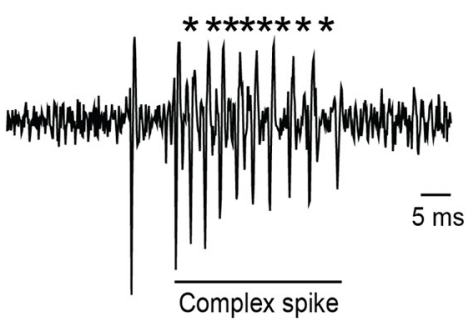

Figure 1. Recording neural activity in the RN. $\boldsymbol{A}$, lllustration of a head-fixed rat pup in the recording apparatus. $\boldsymbol{B}$, Reconstruction of electrode placements (blue vertical lines) within the RN in three successive coronal sections for all pups in the study $(N=8)$.C, Left, Coronal brain section stained with cresyl violet. Red vertical line is the trace of the Dil-coated electrode positioned through the RN. Middle, Representative recordings of MUA in the RN from three successive electrode sites (top traces) and EMG recordings from the contralateral forelimb (bottom trace). The unit activity contained within the dashed box is magnified at right to reveal a burst of action potentials with $\mid \mathrm{Sls} \leq 8 \mathrm{~ms}$, defined here as a complex spike. PAG, Periaqueductal gray; $3 \mathrm{~N}$, oculomotor nucleus; $I V$, fourth ventricle; $M$, medial; $V$, ventral.

tion of twitches early in development. Based on findings that the RN also processes sensory information (Padel et al., 1988), we further hypothesized that RN neurons receive reafference from sleep-related twitches. The present study identifies for the first time the RN as a generator of twitching in infancy. Notably, the processing of reafferent neural signals in the RN during twitching suggests that twitches contribute to sensorimotor integration and topographic organization within the RN and associated neural structures (Dypvik and Bland, 2004).

\section{Materials and Methods}

All experiments were conducted in accordance with the National Institutes of Health (NIH) Guide for the Care and Use of Laboratory Animals (NIH Publication No. 80-23) and were approved by the Institutional Animal Care and Use Committee of the University of Iowa.

\section{Subjects}

A total of 16 7-8-d-old male and female Sprague Dawley rats from 14 litters were used. If littermates were used, they were always assigned to different experimental conditions. Litters were culled to eight pups within $3 \mathrm{~d}$ after birth. Mothers and their litters were housed in laboratory cages $(48 \times 20 \times 26 \mathrm{~cm})$ where food and water were available ad libitum. Animals were maintained on a $12 \mathrm{~h}$ light/dark cycle (lights on: 7:00 A.M.).

Spontaneous and evoked activity in the $R N$

Surgery. Eight pups were prepared using methods described previously (Karlsson et al., 2005). Briefly, under $2-5 \%$ isoflurane anesthesia, a custom-built stainless steel head-fix apparatus was glued to the skull with cyanoacrylate adhesive gel. Bipolar EMG electrodes (50 $\mu \mathrm{m}$ diameter; California Fine Wire) were implanted into the nuchal muscle, the gastrocnemius muscle of the hindlimb, and the triceps brachii muscle of the forelimb contralateral to the neural recording site. After surgery, pups were transferred to an incubator and maintained at thermoneutrality $\left(35^{\circ} \mathrm{C}\right)$ for $1 \mathrm{~h}$ to recover. After recovery, pups were secured in a stereotaxic apparatus (David Kopf Instruments) and briefly anesthetized again. A small hole was drilled in the skull to allow for later insertion of the electrode into the RN (coordinates in relation to bregma: anteroposterior, $-4.8-5.0 \mathrm{~mm}$; lateromedial, $\pm 0.4 \mathrm{~mm}$; dorsoventral, $4.3-4.5 \mathrm{~mm}$ ). Two additional holes were drilled at a location distant from the first one for subsequent insertion of a ground wire and a thermocouple to monitor brain temperature.

Procedure. As described previously (Karlsson et al., 2005), electrophysiological recordings were conducted in a stereotaxic apparatus with the animal's torso secured to a platform and the tail and limbs dangling freely (Fig. 1A). Brain temperature was monitored using a fine-wire thermocouple (Omega Engineering) and maintained at $36-37^{\circ} \mathrm{C}$. A $90 \mathrm{~min}$ acclimation period allowed pups sufficient time to begin exhibiting organized sleep-wake cycles.

The EMG bipolar electrodes were connected to a differential amplifier (A-M Systems; amplification, 10,000×; filter setting, 300-5000 Hz). Recordings of multiunit activity (MUA) in the RN were acquired using 16-channel silicon depth electrodes ( $100 \mu \mathrm{m}$ vertical separation between recording sites; NeuroNexus), with impedances ranging from 1 to $4 \mathrm{M} \Omega$, connected to a data acquisition system (Tucker-Davis Technologies) that 
amplified $(10,000 \times)$ and filtered the signals. MUA signals were filtered using a $500-5000 \mathrm{~Hz}$ bandpass filter and a $60 \mathrm{~Hz}$ notch filter. Neural and EMG signals were recorded at sampling rates of 12.5 and $1 \mathrm{kHz}$, respectively, using a digital interface and Spike2 software (Cambridge Electronic Design). Before insertion into the brain, the tip of the electrode was dipped in fluorescent DiI (Invitrogen Life Technologies) for subsequent histological confirmation of the recording sites. $\mathrm{An} \mathrm{Ag} / \mathrm{AgCl}$ ground electrode (Medwire; $0.25 \mathrm{~mm}$ diameter) was placed in the contralateral occipital cortex.

Before recording spontaneous activity in the RN, we determined whether stimulation of the contralateral forelimb yielded consistent $\mathrm{RN}$ responses in $\geq 1$ recording channel; this test served to confirm electrode placement within an $\mathrm{RN}$ region specifically related to forelimb processing. To perform these forelimb stimulations, a fine paintbrush was used to gently flex the forelimb at the elbow (Tiriac et al., 2014). When consistent evoked responses were confirmed, spontaneous RN and EMG activity during sleep and wakefulness was recorded continuously over a 30 min session. During the recording session, the experimenter scored the pup's wake movements and twitches using computer key presses that registered events in synchrony with the electrophysiological record (Karlsson et al., 2005).

At the end of the $30 \mathrm{~min}$ recording of spontaneous activity, the experimenter systematically assessed $\mathrm{RN}$ responses to peripheral exafferent stimulation of the forelimb. Stimulations were repeated for $10 \mathrm{~min}$ with interstimulus intervals of 5-10 s. The experimenter marked each stimulus event using a computer key press.

Data analysis. Spike2 software (Cambridge Electronic Design) was used for spike sorting using template matching and principle components analysis as described previously (Sokoloff et al., 2014). Units were only assigned to a template if their amplitude exceeded a required threshold (signal-to-noise ratio, $\geq 2: 1$ ). Waveforms that exceeded 3.5 SDs from the mean of a given template were excluded from further analysis. After spike sorting was complete, burst analyses were performed using a script written for Spike2. Based on the distributions of interspike intervals (ISIs), complex spikes were defined as burst events with ISIs $\leq 8 \mathrm{~ms}$ (Fig. $1 C)$. All noncomplex-spike events were defined as simple spikes.

Periods of sleep and wakefulness were identified using previously described methods (Karlsson et al., 2005; Mohns and Blumberg, 2010; Sokoloff et al., 2014; Tiriac et al., 2014). Briefly, EMG records were rectified and five $1 \mathrm{~s}$ EMG segments each of atonia and high tone were used to calculate mean amplitude of the EMG signal. Then, the midpoint between the two was used to determine a threshold for defining behavioral state. Active wake was defined by the presence of high-amplitude limb movements against a background of high nuchal muscle tone and active sleep was defined by the presence of twitches against a background of muscle atonia (Seelke and Blumberg, 2008; Blumberg and Seelke, 2010). Myoclonic twitches were defined electrographically as EMG events that exceeded by $\geq 3 \times$ the mean EMG baseline during atonia (Mohns and Blumberg, 2010; Sokoloff et al., 2014; Tiriac et al., 2014). Because our focus here was on movement-related RN activity, and because RN activity was predominantly associated with movement, we did not include periods of quiet sleep or quiet wake in our analyses.

The temporal relationship between twitches and unit activity was examined as follows. First, for each individual unit and using forelimb twitches as trigger events, we produced perievent histograms using the "event correlation" function in Spike2. These analyses were performed independently for complex and simple spikes using $10 \mathrm{~ms}$ bins and $1 \mathrm{~s}$ windows. To test for statistical significance of each event correlation, we jittered twitch events 1000 times within a $1 \mathrm{~s}$ window using PatternJitter (Harrison and Geman, 2009; Amarasingham et al., 2012) implemented in MatLab. We corrected for multiple comparisons using the method of Amarasingham et al. (2012). This method generates upper and lower confidence bands for each event correlation ( $p<0.01$ for each band).

To determine whether neural activity preceded or followed twitches, we identified the first time bin in each event correlation that surpassed the established $99 \%$ upper threshold for statistical significance. Next, based on this identification, we classified simple and complex spikes as twitch preceding or twitch following. Finally, we pooled data for simple and complex spikes across pups within each category and performed event correlations and statistical tests as described above.

We next determined the temporal relationship between RN activity and wake-related movements. Because there were relatively few wake movements in our records, it was not possible to perform jitter analyses on event correlations for individual units. Therefore, we analyzed wakerelated unit activity using the pooled populations of twitch-preceding and twitch-following simple and complex spikes identified above. We first determined the onset of forelimb movements during wake bouts. We defined movement onset on the basis of the EMG signal surpassing an established threshold (i.e., $\geq 3 \times$ the value of EMG baseline during atonia for $\geq 1 \mathrm{~s}$ ); movement offset occurred when the EMG signal passed below the threshold. Next, we produced wake-movement-triggered perievent histograms and performed jitter analyses on the pooled data as described above. Because wake movements are longer in duration than twitches, we used $50 \mathrm{~ms}$ bins and $2 \mathrm{~s}$ windows.

To assess RN topography, we identified those units that exhibited significant forelimb-related twitch-preceding or twitch-following activity. We then repeated the event correlation analyses described above for each of these units, but now using nuchal or hindlimb twitches as triggers. Next, for each available unit, we used event correlations and jitter analysis to determine whether unit activity exhibited a significant relationship with forelimb, nuchal, or hindlimb twitches (defined as having $\geq 1$ significant bin in its perievent histogram). We then used independent $\chi^{2}$ tests (SPSS) to assess differences in the percentage of units that were twitch-related between muscle groups. Finally, to help interpret these relationships, we performed event correlations to determine the temporal relationships between muscle groups (bin size, $10 \mathrm{~ms}$; window size, $1 \mathrm{~s})$. For this last analysis, we only examined those subjects for which all three EMGs were available $(N=5)$.

To analyze unit activity in response to forelimb stimulation, perievent histograms were constructed as described above using $10 \mathrm{~ms}$ bins and $1 \mathrm{~s}$ windows. For each unit, the first 30 stimulations were analyzed and perievent histograms were triggered on the stimulation-related onset of forelimb EMG activity. Statistical significance was again tested using the jittering method described above. For these and all other analyses, and unless otherwise indicated, means are presented with their SEs.

\section{Effect of pharmacological inactivation of the RN on motor behavior during sleep and wake}

Surgery. Eight head-fixed pups were used in this experiment. All surgical procedures were similar to those described for the first experiment. After recovery from surgery, the pups were placed in the stereotaxic apparatus in a thermoneutral environment acclimated until they exhibited organized sleep-wake cycles. For this experiment, EMG bipolar electrodes were inserted into the nuchal muscle and both triceps brachii of the forelimbs.

Procedure. After the 90 min acclimation period in the stereotaxic apparatus, baseline activity was recorded for $30 \mathrm{~min}$ (see Fig. $5 \mathrm{~A}$ ). The needle of a $0.5 \mu \mathrm{l}$ microsyringe (Hamilton) was dipped in fluorescent DiI (for subsequent histological confirmation of the infusion site) and lowered stereotaxically into the RN. Pups ( $N=4$ per group) received a $0.1 \mu \mathrm{l}$ unilateral infusion into the left or right $\mathrm{RN}$ of either a drug mixture composed of the $\mathrm{GABA}_{\mathrm{A}}$ receptor agonist muscimol, the $\mathrm{GABA}_{\mathrm{B}}$ receptor agonist baclofen, and the glycine receptor agonist $\beta$-alanine (Cocktail group; Sigma-Aldrich; all drugs at $10 \mathrm{~mm}$, dissolved in $0.9 \%$ physiological saline), or physiological saline (VEH group; $0.9 \%$; the infusion volume needed to target the $\mathrm{RN}$ in its entirety was determined previously in several additional pups using a microsyringe filled with either fluorescently tagged muscimol or DiI diluted in saline). Drug or vehicle solutions were infused at a rate of $0.1 \mu \mathrm{l} / \mathrm{min}$. A $40 \mathrm{~min}$ postinfusion period allowed for diffusion of the solution and acclimation of the pup before the final $30 \mathrm{~min}$ recording session. Behavior and EMG activity were monitored continuously over the entire experimental session.

Our choice of GABA and glycine agonists was based on previous studies in rats showing that the inhibitory effects of GABA in the rat $\mathrm{RN}$ are mediated by both $\mathrm{GABA}_{\mathrm{A}}$ and $\mathrm{GABA}_{\mathrm{B}}$ (but not $\mathrm{GABA}_{\mathrm{C}}$ ) receptors ( $\mathrm{Ci}$ ranna et al., 2003). Additionally, glycine receptors have been found in the rat RN (Sato et al., 1991) and linked to inhibitory effects in the adult cat 


\section{A Evoked activity}

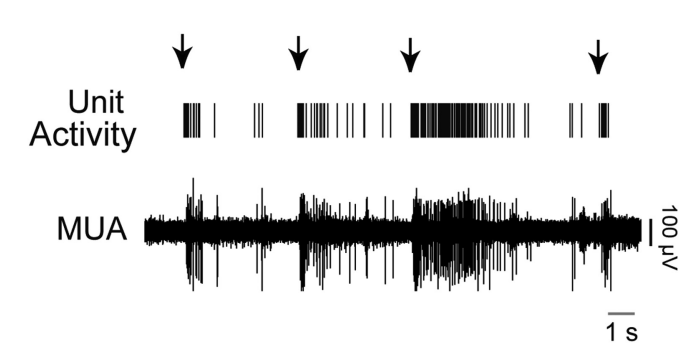

\section{B Spontaneous activity}

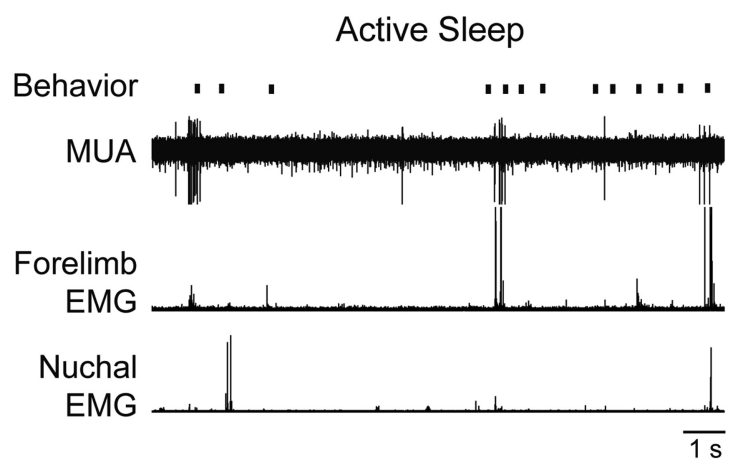

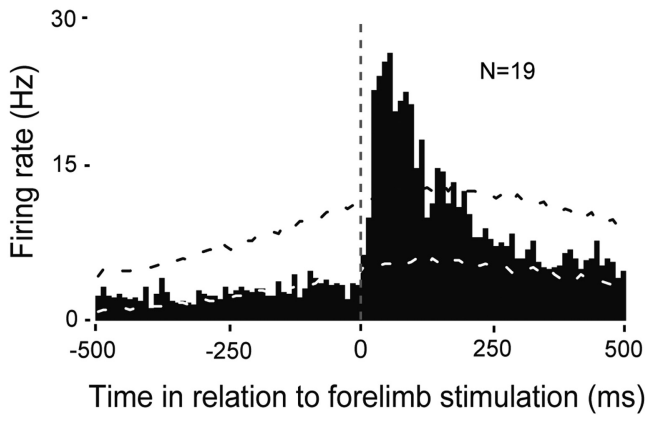

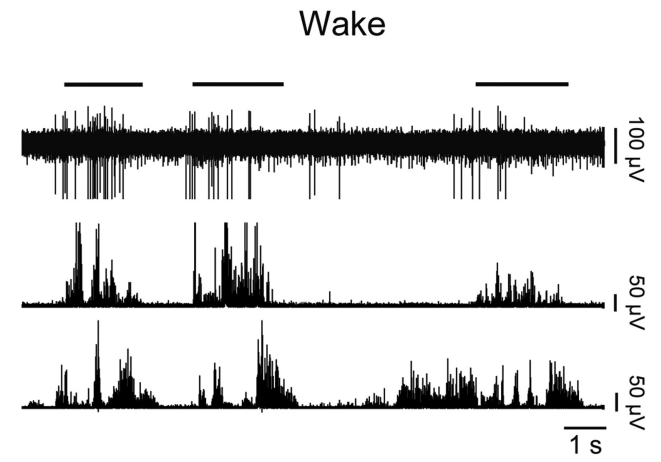

Figure 2. Evoked and spontaneous activity in the RN during sleep and wakefulness. $\boldsymbol{A}$, Left, Representative recordings from the RN showing evoked sorted unit activity and MUA in response to contralateral forelimb stimulation (arrows). Right, Perievent histogram depicting mean firing rates of RN neurons in relation to contralateral forelimb stimulation. Data were pooled across all subjects $(N=8)$ and units $(N=19)$. Upper and lower confidence bands ( $p<0.01$ for each band) are indicated by the black and white dashed lines, respectively. Vertical dashed line corresponds to stimulation onset determined using forelimb EMG activity. $\boldsymbol{B}$, Representative data depicting spontaneous behavior (vertical ticks, twitches; horizontal lines, wake movements), MUA, and contralateral forelimb and nuchal EMG activity during active sleep (left) and wake (right).

(Altmann et al., 1973) and mouse (Jiang et al., 2002). Finally, Brooks and Peever (2012) used combined pharmacological manipulation of $\mathrm{GABA}_{\mathrm{A}}$, $\mathrm{GABA}_{\mathrm{B}}$, and glycine receptors in trigeminal motoneurons to modulate twitching of the masseter muscle in adult rats.

Data analysis. For the 30 min preinfusion and postinfusion periods, we quantified for each pup the mean time spent in active sleep. A bout of active sleep was defined as the time from the first twitch after the onset of atonia to the increase in muscle tone indicative of wakefulness (Seelke and Blumberg, 2008). Although RN inactivation reduced the number of twitches expressed, there were sufficient numbers of twitches to define active sleep bouts. In addition, we quantified the number of wake bouts as well as the mean sleep-wake cycle length (defined as the time between successive wake-bout onsets). To assess group effects on the above variables, $2 \times 2$ repeated-measures factorial ANOVAs (SPSS, IBM) with the experimental group (Cocktail or VEH) as the between-subjects factor and time [preinfusion (Pre) or postinfusion (Post)] as the repeated-measures factor were performed. Time spent in active sleep, number of wake bouts, and sleep-wake cycle length were used as dependent variables.

To calculate twitching rates, the total number of forelimb twitches for each pup was divided by the total time in active sleep. The total number of wake-related forelimb movements in each session was also quantified using the EMG record. To assess the effect of the experimental manipulation, we performed a $2 \times 2$ repeated-measures factorial ANOVA with experimental group (Cocktail or VEH) as the between-subjects factor and time (Pre or Post) as the repeated-measures factor. Rate of twitching and number of wake-related movements were the dependent variables. To assess the temporal patterns of forelimb twitching before and after RN inactivation, we determined all intertwitch intervals (ITIs) during active sleep and then estimated the survival function for each ITI. For the survival test, group and time were used as independent factors for both ipsilateral and contralateral forelimb activity, and a generalized Wilcoxon test (Breslow; SPSS) was used to determine differences in the survival distribution of ITIs for the different sessions in each group. Alpha was set at 0.05 .

\section{Histology}

At the end of each experiment, pups were overdosed with sodium pentobarbital $(1.5 \mathrm{mg} / \mathrm{g})$ and perfused transcardially with PBS followed by $4 \%$ paraformaldehyde. Coronal brain sections were sliced ( $80 \mu \mathrm{m} \mathrm{sec}-$ tions) using a freezing microtome (Leica Microsystems). Electrode and microsyringe placements within the $\mathrm{RN}$ were verified by visualizing the DiI tract at 2.5-5 $\times$ magnification using a fluorescent microscope (Leica Microsystems). Subsequent staining with cresyl violet was used for further confirmation of electrode or microsyringe placement in the RN.

\section{Results}

Evoked and spontaneous activity in the RN

Extracellular neuronal activity in the $\mathrm{RN}$ was recorded from eight postnatal day (P) 7-P8 pups yielding a total of 27 units (range, 2-5 units per pup). Histology confirmed that electrodes were located in the RN (Fig. $1 B, C$ ). Figure $1 C$ illustrates the relationship between RN activity and twitching in the contralateral forelimb. In addition to single spikes of activity with ISIs $>8 \mathrm{~ms}$, designated here as simple spikes, $\mathrm{RN}$ activity was also characterized by short bursts of activity that we designated as complex spikes (Lisman, 1997). Complex spikes were composed of 2-11 individual action potentials with ISIs of $2-8 \mathrm{~ms}$ (mean, $2.4 \mathrm{~ms}$; $\mathrm{SD}, 0.9 \mathrm{~ms}$ ). It should be noted that the complex spikes described here have very similar characteristics to the bursts previously described as being well suited for efficient transmission of neural information (Lisman, 1997). 


\section{Complex spikes}
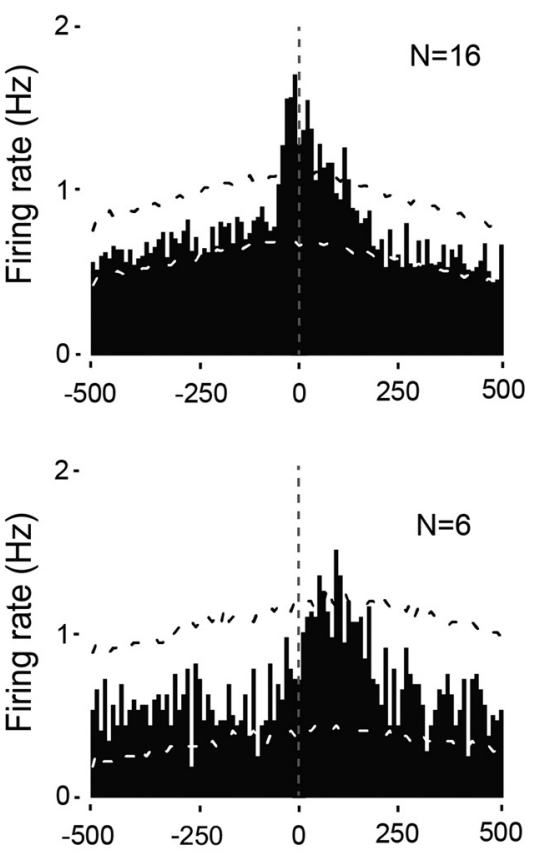

Time in relation to forelimb twitch (ms)

\section{Simple spikes}
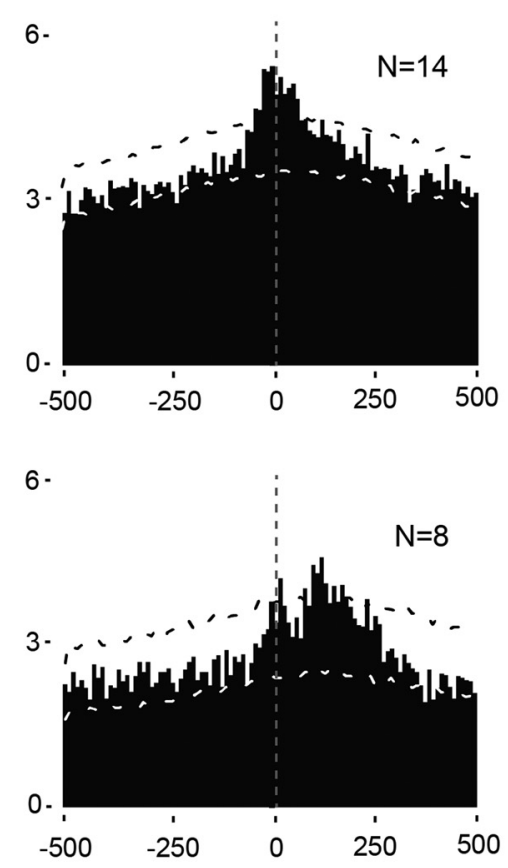

Time in relation to forelimb twitch (ms)

Figure 3. Patterns of twitch-related complex and simple spike activity in the RN. Perievent histograms for complex spikes (left) and simple spikes (right) in relation to contralateral forelimb twitches. Top row, Data pooled across all units with increases in neural activity that significantly preceded twitches. Bottom row, Data pooled across all units that significantly increased activity following twitches. Vertical dashed lines correspond to twitch onset. Number of units included in each analysis is indicated in each plot. Upper and lower confidence bands ( $p<0.01$ for each band) are indicated by the black and white dashed lines, respectively.

\section{Evoked activity in the $R N$}

Contralateral forelimb stimulation triggered sensory responses at a minimum of one electrode site per pup, and in 19 of 27 units overall $(70.3 \%)$. Figure $2 \mathrm{~A}$ depicts, for a representative $\mathrm{RN}$ unit, the relationship between forelimb stimulation and neural activity. Across all units that were responsive to exafference, $\mathrm{RN}$ activity increased significantly shortly after stimulation $(p<0.01)$ with a mean latency of $39 \pm 5 \mathrm{~ms}(N=19$; Fig. $2 A$, right $)$. In contrast, stimulation of the contralateral hindlimb and ipsilateral forelimb did not trigger reliable neural activity in the units analyzed here.

\section{Spontaneous activity in the $R N$}

Figure $2 B$ shows, for a representative $\mathrm{RN}$ unit, the relationship between spontaneous sleep-wake cycling and neural activity. During spontaneous cycling, and regardless of behavioral state, the RN neuron is phasically active during contralateral forelimb movements. Whereas short trains of activity predominated during bouts of active sleep, activity accompanying wake-related movements was longer in duration and consisted of sustained tonic firing that terminated shortly before movement offset (Fig. $2 B$ ). When the pups were not actively moving their limbs, RN activity was substantially reduced and often absent (Figs. 1C, 2B).

The temporal relationship between unit activity in the RN and contralateral forelimb twitches revealed three clear subpopulation of neurons: (1) neurons that fired before movement onset, (2) neurons that fired after movement onset, and (3) neurons that did not show any significant relationship with contralateral forelimb movements. Unit activity from neurons in the last group $(N=5)$ was excluded from further analysis. Across all units that significantly increased their firing rates before twitch onset, they did so with a mean latency of $22 \pm 3 \mathrm{~ms}$ for complex spikes $(N=16)$ and $30 \pm 5 \mathrm{~ms}$ for simple spikes $(N=14$; Fig. 3 , top row). It should be noted that both complex and simple spike activity in this group also exhibited a significant, discrete peak of activity shortly after twitch onset. For those units that increased their firing rates only after twitch onset, they did so with a mean latency of $80 \pm 16 \mathrm{~ms}$ for complex spikes $(N=6)$ and $91 \pm 15 \mathrm{~ms}$ for simple spikes ( $N=8$; Fig. 3, bottom row).

Across all units that consistently fired before the onset of forelimb twitches, firing rates increased significantly before contralateral forelimb wake movements with a mean latency of $50 \pm$ $17 \mathrm{~ms}$ for complex spike activity $(N=16$; Fig. 4 , top left $)$ and $55 \pm 8 \mathrm{~ms}$ for simple spikes ( $N=14$; Fig. 4 , top right). The group of neurons that fired predominantly after wake movement onset showed a mean ( \pm SEM) latency of $208 \pm 46 \mathrm{~ms}$ for both complex spikes $(N=6$; Fig. 4, bottom left $)$ and $118 \pm 35 \mathrm{~ms}$ for simple spikes ( $N=8$; Fig. 4 , bottom right). Finally, as the above analyses suggest, we found that complex and simple spikes were equally likely to be associated with twitches as with wake-related movements.

\section{Topographic organization of the $R N$}

For each of the forelimb units that exhibited significant twitchpreceding or twitch-following activity (Fig. 3), we repeated the analyses using nuchal and hindlimb twitches as triggers (Fig. 5A). In general, whereas forelimb twitches were associated with substantial twitch-preceding and twitch-following activity for both complex and simple spikes, only preceding-activity for the nuchal muscle exhibited a clear twitch-related pattern. Next, across all units with available EMG records, we determined whether they exhibited significant twitch-related activity profiles. Figure 


\section{Complex spikes}
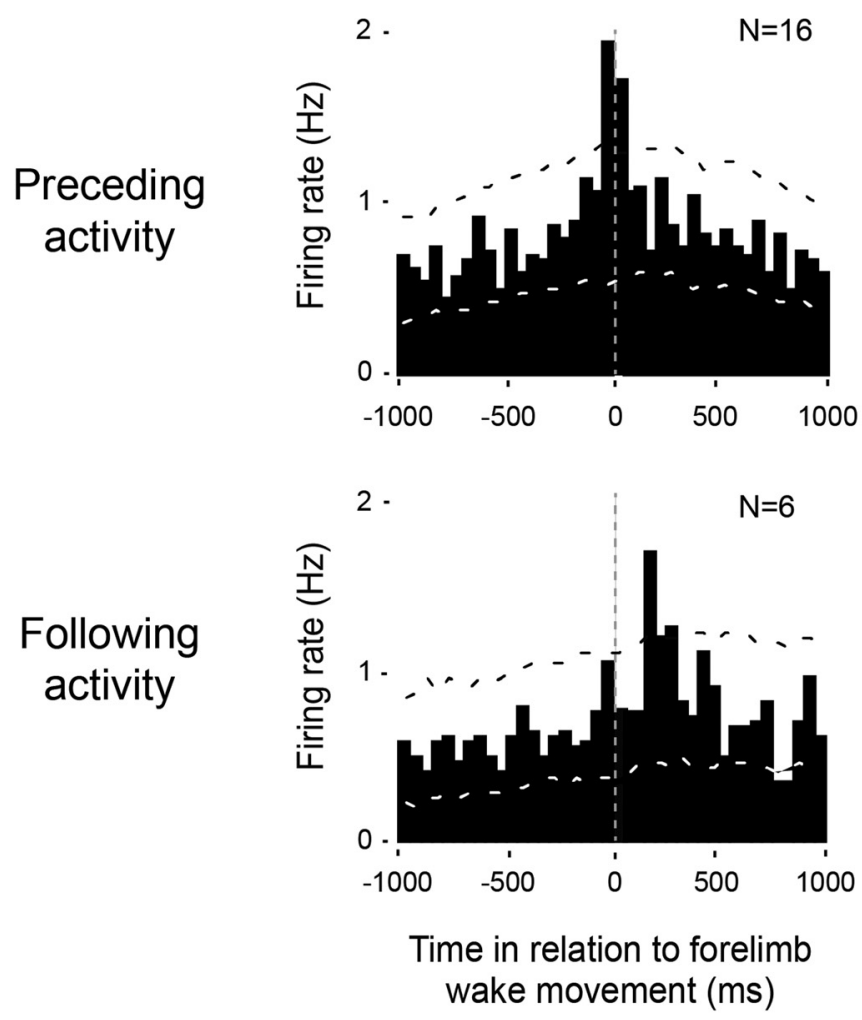

Simple spikes
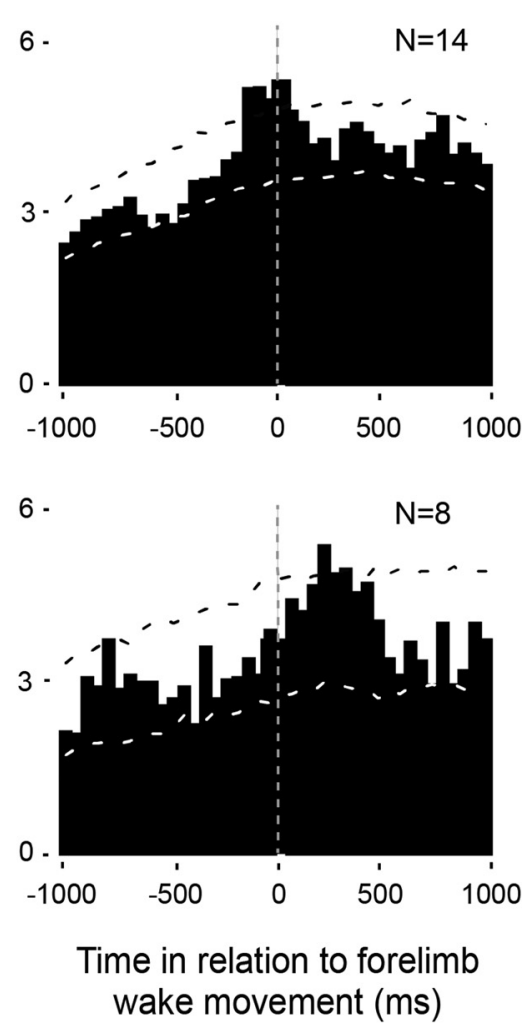

Figure 4. Patterns of wake-movement-related complex and simple spike activity in the RN. Perievent histograms for complex spikes (left) and simple spikes (right) in relation to the onset of the first forelimb movement during a bout of wakefulness. Top row, Data pooled across all units that significantly preceded forelimb movements. Bottom row, Data pooled across all units that significantly followed forelimb movements. Vertical dashed lines correspond to movement onset. Number of units included in each analysis is indicated in each plot. Upper and lower confidence bands ( $p<0.01$ for each band) are indicated by the black and white dashed lines, respectively.

$5 B$ presents the percentage of units exhibiting significant twitchrelated activity (i.e., twitch-preceding or twitch-following) for each muscle group. For both complex and simple spikes, there was a strong topographic relationship between unit activity and forelimb twitching, a weaker relationship with nuchal twitching, and an even weaker relationship with hindlimb twitching. The differences in the percentage of significant twitch-related units were statistically significant (forelimb vs nuchal: complex spikes, $\chi_{(1,54)}^{2}=5.3, p<0.03$; simple spikes, $\chi_{(1,54)}^{2}=9.4, p<0.01$; forelimb vs hindlimb: complex spikes, $\chi_{(1,45)}^{2}=18.3, p<0.001$; simple spikes, $\left.\chi_{(1,45)}^{2}=10.6 p<0.002\right)$.

The preceding data (see Fig. $5 A, B$ ) suggest that the forelimb and nuchal muscles are more functionally integrated (or less differentiated) than the forelimb and hindlimb muscles. To examine this possibility, we cross-correlated twitch events for the forelimb, nuchal, and hindlimb muscles for those subjects with EMG records from all three muscle groups (Fig. $5 C$ ). Consistent with the above suggestion, this analysis revealed a stronger relationship between the forelimb and nuchal muscles than between the forelimb and hindlimb muscles.

Finally, in one P8 rat (Fig. 5D), we recorded from an RN unit that responded preferentially to twitches of the contralateral forelimb, and from another unit (located $\sim 200 \mu \mathrm{m}$ ventral to the first) that responded preferentially to twitches of the contralateral hindlimb; neither unit responded strongly to twitches of the nuchal muscle.
Effect of pharmacological inactivation of the RN on motor behavior during sleep and wake

To assess the causal role of the infant $\mathrm{RN}$ in the production of twitches, we selectively inactivated the RN by infusing a cocktail of $\mathrm{GABA}_{\mathrm{A}}, \mathrm{GABA}_{\mathrm{B}}$, and glycine receptor agonists. For all pups after the experiment, the placement of the microsyringe was histologically verified as being located within the RN.

Pups infused with vehicle continued to cycle regularly between sleep and wake (Fig. 6A). In contrast, all four pups infused with the cocktail exhibited an acute reaction characterized by elevated muscle tone and behavioral activation averaging $20.9 \pm$ $5.3 \mathrm{~min}$ (Fig. 6A). During this period, isolated twitches against a background of high muscle tone were sometimes observed. After the $30 \mathrm{~min}$ postinfusion acclimation period, the acute response had subsided and organized sleep-wake cycles resumed. Comparisons of mean duration of active sleep (VEH Pre: $1150.5 \pm$ 147.8 s; VEH Post: $1228.3 \pm 110.6$ s; Cocktail Pre: $1040.2 \pm 113.6$ s; Cocktail Post: $1276.5 \pm 86.2 \mathrm{~s}$ ), mean number of wake bouts (VEH Pre: $28.7 \pm 3.6$; VEH Post: $29.0 \pm 4.2$; Cocktail Pre: $25.0 \pm$ 4.1; Cocktail Post: $21.7 \pm 5.1$ ), and mean length of sleep-wake cycles (VEH Pre: $63.3 \pm 7.7$ s; VEH Post: $65.8 \pm 10.3$ s; Cocktail Pre: $67.9 \pm 8.5$ s; Cocktail Post: $75.2 \pm 14.8$ s) indicated no significant main effects or interactions (all $p>0.05$ ).

Cocktail infusion markedly decreased twitching rates during active sleep in both the ipsilateral and contralateral forelimbs (Fig. 6B, top row). We found significant main effects of Pre/Post (ipsilateral: $F_{(1,6)}=11.93, p<0.02, \eta^{2}=0.30$ : con- 
A

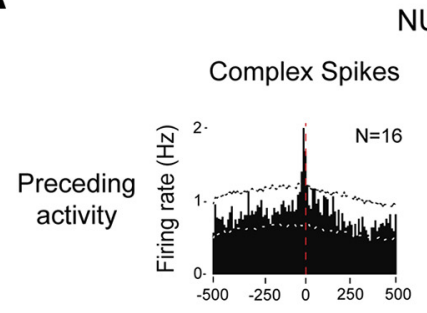

NUCHAL

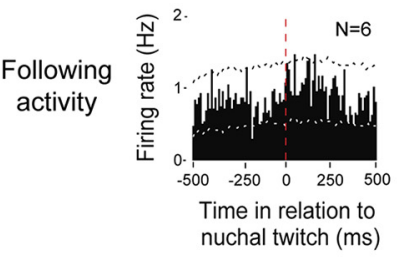

B

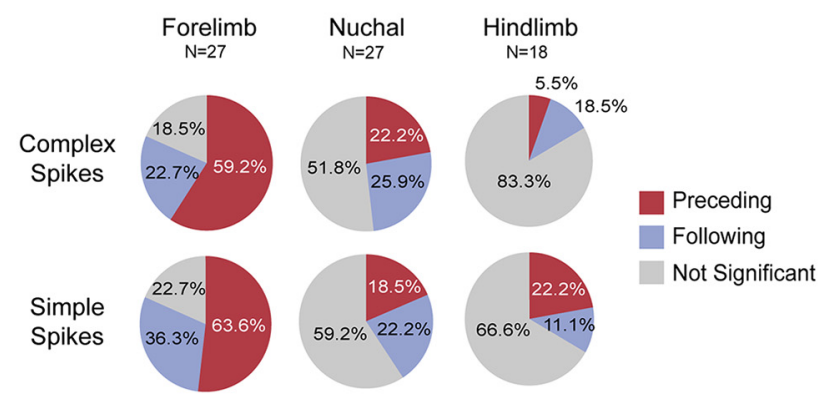

C

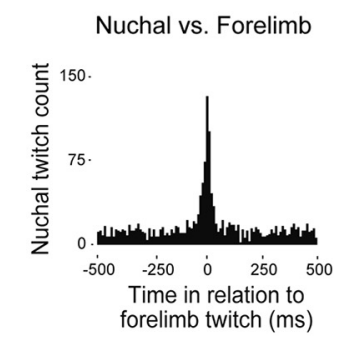

Simple Spikes

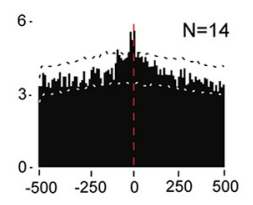

6 .

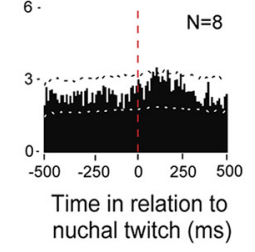

HINDLIMB
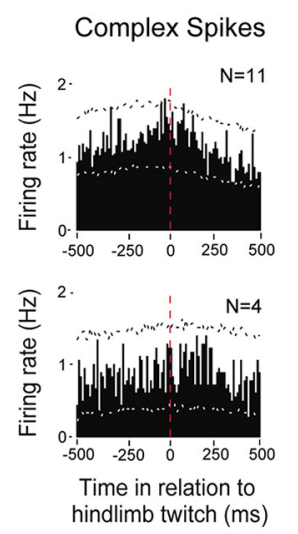

Simple Spikes

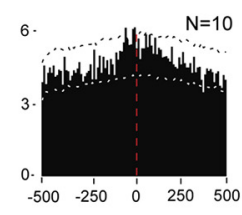

6 .

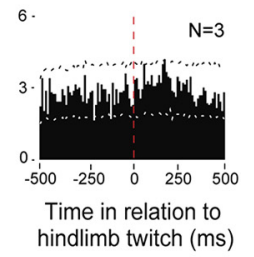

D

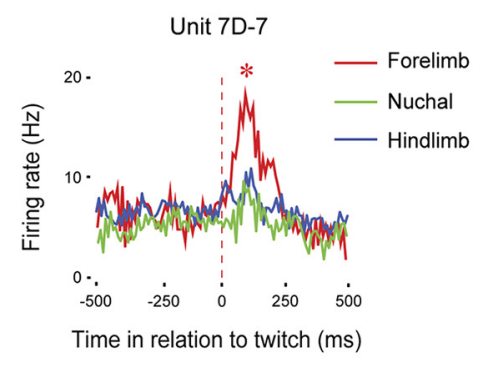

Unit 7D-5

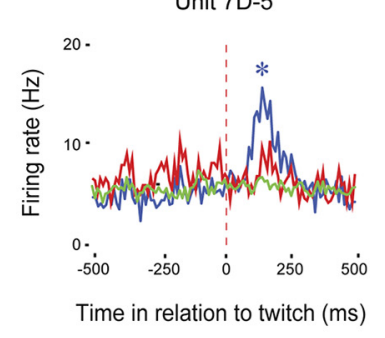

Figure 5. Somatotopic organization of twitch-related activity in the RN. $\boldsymbol{A}$, Perievent histograms depicting unit activity in relation to contralateral nuchal (left) and hindlimb (right) twitches. Each histogram was created using pooled data from units that exhibited significant activity in relation to forelimb twitches (see Fig. 3). Vertical dashed lines correspond to twitch onset. Number of units included in each analysis is indicated in each plot. Upper and lower confidence bands ( $p<0.01$ for each band) are indicated by the black and white dashed lines, respectively. $\boldsymbol{B}$, Percentage of units exhibiting significant or nonsignificant twitch-related activity for each muscle group. $\boldsymbol{C}$, Perievent histograms showing the number of nuchal (left) and hindlimb (right) twitches in relation to forelimb twitches for those subjects with EMG data from all three muscle groups $(N=5)$. $\boldsymbol{D}$, Perievent line histograms relating activity in two adjacent units to twitches in the contralateral forelimb muscle (red), contralateral nuchal muscle (green), and hindlimb muscle (blue). Vertical dashed lines correspond to twitch onset. Asterisks indicate significant peaks in unit firing rate, $p<0.01$.

tralateral: $\left.F_{(1,6)}=6.59, p<0.05, \eta^{2}=0.19\right)$ as well as a Group $\times$ Pre/Post interaction (ipsilateral: $F_{(1,6)}=6.82, p<$ 0.05, $\eta^{2}=0.17$; contralateral: $F_{(1,6)}=11.41, p<0.02, \eta^{2}=$ 0.33 ; all medium-to-large effect sizes, as indicated by $\eta^{2}$; Cohen, 1988). In contrast, rates of twitching in the vehicleinfused pups did not change after infusion for both the contralateral and ipsilateral forelimbs.

Next, we determined whether the temporal patterning of twitching was altered by cocktail infusion (Fig. 6B, bottom row). Log-survivor analysis revealed that longer ITIs were more prominent after drug infusion (contralateral: $\chi_{(1,4)}^{2}=$ 196.96, $p<0.001$; ipsilateral: $\left.\chi_{(1,4)}^{2}=164.99, p<0.001\right)$. This effect was not present in the vehicle group, where ITIs remained constant between the preinfusion and postinfusion sessions.

As expected, the total number of wake-related forelimb movements decreased over the $30 \mathrm{~min}$ postinfusion recording session. Specifically, the total number of forelimb wake movements dur- ing the preinfusion session (contralateral: $70 \pm 11.24$; ipsilateral: $61.5 \pm 12.06$ ) was less than during the postinfusion session (contralateral: $25 \pm 4.05$; ipsilateral: $27.75 \pm 5.18)$. There was a significant main effect of Pre/Post (contralateral: $F_{(1,6)}=16.54, p<$ $0.01, \eta^{2}=0.26$; ipsilateral: $\left.F_{(1,6)}=13.44, p<0.02, \eta^{2}=0.26\right)$, as well as a Pre/Post $\times$ Group interaction (contralateral: $F_{(1,6)}=$ 9.13, $p<0.03, \eta^{2}=0.19$; ipsilateral: $F_{(1,6)}=11.42, p<0.05, \eta^{2}$ $=0.18)$. It is also important to note that forelimb wake movements after inactivation were noticeably weaker and generally shorter in duration than those in the baseline or exhibited by intact pups.

\section{Discussion}

Sensory feedback arising from myoclonic twitches is thought to play an important role in driving early sensorimotor development (Petersson et al., 2003; Khazipov et al., 2004; Mohns and Blumberg, 2008; Tiriac et al., 2012, 2014; Blumberg et al., 2013a; Sokoloff et al., 2014). With the exception of several studies in 
A

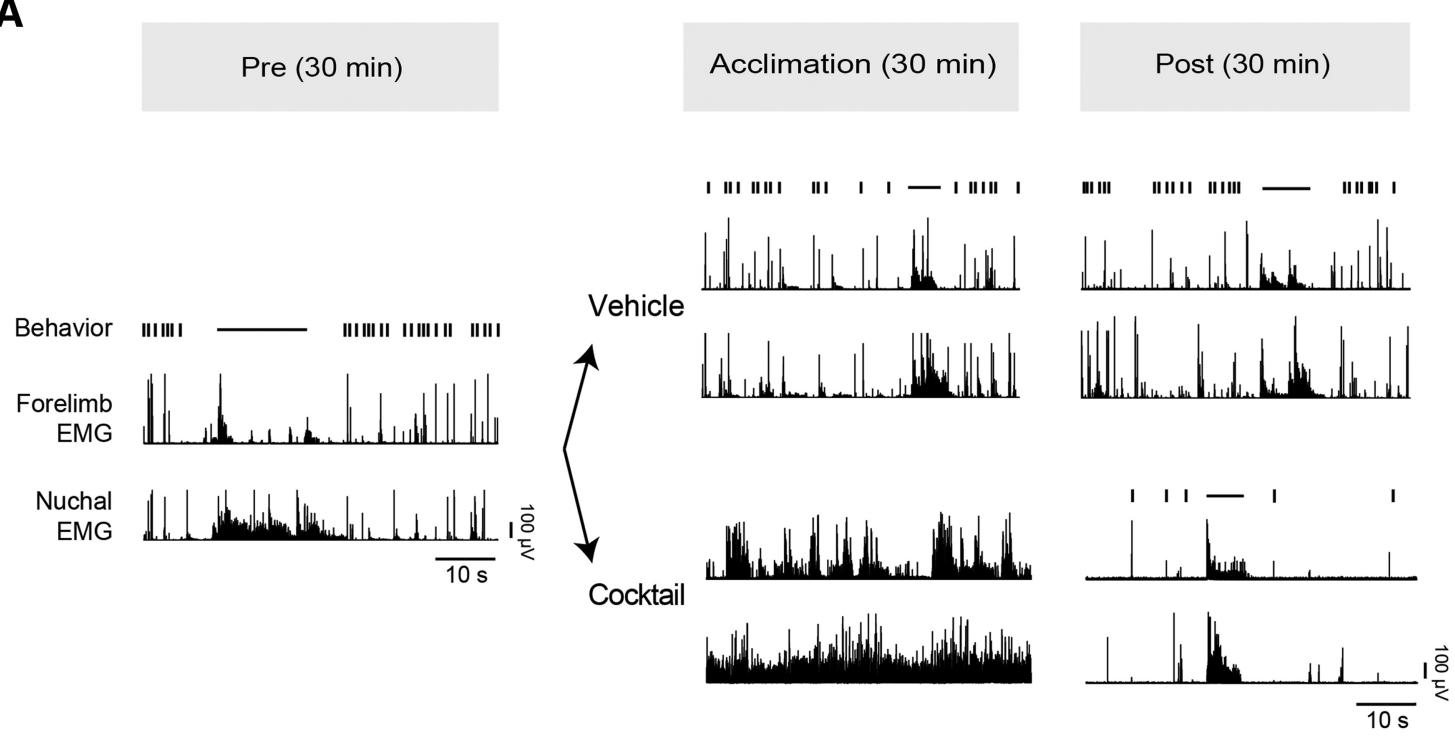

B

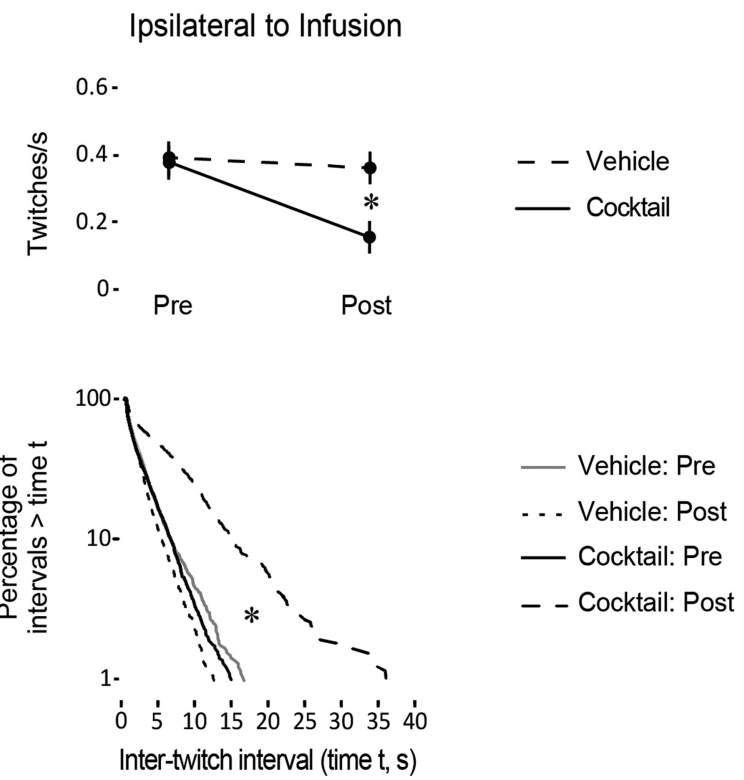

Contralateral to Infusion
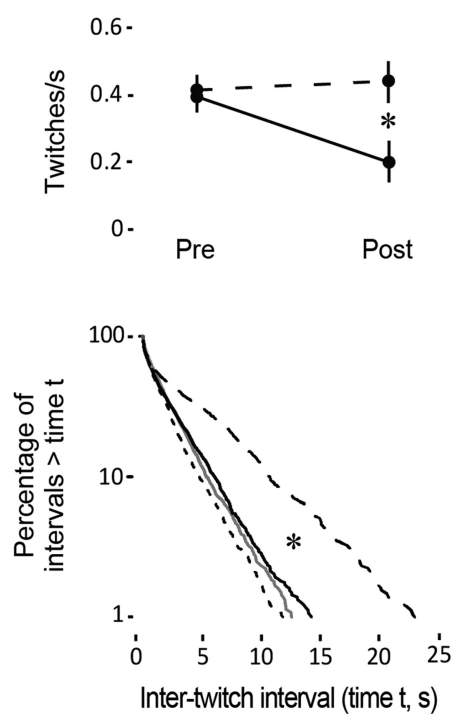

Figure 6. Effects of pharmacological inhibition of the RN on sleep-related twitching. $A$, Top, Timeline depicting the phases of the experiment before (Pre) and after (Post) infusion of a cocktail consisting of $G_{A B A}, G A B A_{B}$, and glycine receptor agonists or vehicle. Bottom, Representative samples of forelimb and nuchal EMG activity and behavior (twitching, vertical ticks; wake movements, horizontal lines) during the Pre, Acclimation, and Post periods. B, Top row, Mean rate of twitching per unit time in active sleep before and after infusion of the vehicle or cocktail for the forelimb ipsilateral (left) and contralateral (right) to the infusion. Asterisks indicate significant differences, $p<0.05$. Bottom row, Log-survivor plots of ITIs before and after vehicle or cocktail infusions for the forelimb ipsilateral (left) and contralateral (right) to the infusion. Asterisks indicate significant Pre/Post differences for the Cocktail group, $p<0.001$.

adult cats and mice (Gassel et al., 1966; Li and Peever, 2014), the neural pathways and mechanisms involved in the generation of twitches have remained unclear. The present findings show for the first time that the infant RN, traditionally considered a motor structure (Muir and Whishaw, 2000; Hermer-Vazquez et al., 2004; Morris et al., 2015), contributes to the production of twitching and also receives sensory feedback from self-generated movements in a topographic manner.

\section{The role of the $\mathrm{RN}$ in the production of twitches during active sleep}

Previous work in perinatal rats suggests that the spinal circuits that generate twitching progressively come under the control of supraspinal circuits (Kreider and Blumberg, 2000; Robinson et al., 2000; Karlsson et al., 2005). In adult animals, one mesopon- tine nucleus, the sublaterodorsal tegmental nucleus (SLD), plays an important role in producing muscle atonia during active sleep (Peever et al., 2014). However, because the SLD does not produce twitching, other candidate nuclei within the mesopontine region have been postulated to be twitch generators, including the laterodorsal tegmental nucleus, the pedunculopontine tegmental nucleus, and the RN (Karlsson et al., 2005; Peever et al., 2014).

With regard to the $\mathrm{RN}, \mathrm{RN}$ activity in adult cats increases phasically during periods of sleep-related twitching and electrolytic lesions of the RN cause a generalized impairment in twitching that lasts only for several days (Gassel et al., 1966). More recently, pharmacogenetic stimulation of the $\mathrm{RN}$ in adult mice was shown to increase sleep-related twitching of the masseter muscle (Li and Peever, 2014). Here, using infant rats, we also 
demonstrate a causal role for the $\mathrm{RN}$ in twitching. Specifically, we found many RN neurons that increased their activity before the onset of contralateral forelimb twitches, and pharmacological inactivation of the RN using $\mathrm{GABA}_{\mathrm{A}}, \mathrm{GABA}_{\mathrm{B}}$, and glycine receptor agonists substantially reduced the occurrence of twitching. Conversely, combined antagonism of these receptors at trigeminal motoneurons increased twitching of the masseter muscle in adult rats (Brooks and Peever, 2012). Importantly, RN inactivation did not abolish twitching completely, most likely due to the use of a unilateral procedure. In addition, spared twitches could reflect the contributions of other supraspinal (Gassel et al., 1966; Kreider and Blumberg, 2000; Peever et al., 2014) as well as spinal (Blumberg et al., 2013b, 2015) neural circuits.

$\mathrm{RN}$ inactivation reduced twitching in both the contralateral and ipsilateral forelimbs. Even though the most prominent rubrospinal projections are contralateral (Kuypers, 1981), ipsilateral projections have been identified in adult cats (Holstege and Tan, 1988; Stecina et al., 2008). Thus, the bilateral effect on twitching observed here could be due to functional bilateral rubrospinal projections.

During the period immediately following $\mathrm{RN}$ inactivation, we observed an acute motor response consisting of increased muscle tone and limb movements that lasted 10-20 min. This observation was surprising given that all available evidence in adult mice, rats, and cats points to an excitatory role of the RN in motor control (Gassel et al., 1966; Mileykovskiy et al., 2002; Li and Peever, 2014); the present neural recordings also support such an excitatory role for the RN. One possible explanation for the acute response is that the sudden loss of RN activity disinhibited other brainstem motor systems, which quickly compensated for that loss. A second possibility is that the increase in motor activity is the result of a sudden loss of RN activation of gamma motoneurons of muscle spindles (Appelberg, 1962). With a sudden loss of this fusimotor activation, muscle spindles would contract, thus reporting an apparent loss of muscle tone and thereby triggering a compensatory motor response. Regardless, after this acute response, pups resumed organized sleep-wake cycling characterized by decreased rates of twitching.

\section{Processing reafferent feedback to the RN}

The latencies for twitch-related reafference for complex and simple spikes ranged from 10 to $150 \mathrm{~ms}$, suggesting more than one source of feedback from the periphery to the RN. Shorter-latency responses could be due to direct spinorubral connections, as previously reported in cats (Padel and Jeneskog, 1981; Padel and Bourbonnais, 1985). Regarding the longer-latency responses, twitch-related sensory feedback activates the infant rat cerebellum (Sokoloff et al., 2014), after which it could be conveyed from the deep cerebellar nuclei (DCNs) to the RN (Flumerfelt, 1980; Naus et al., 1985). We have observed such direct DCN projections to the $\mathrm{RN}$ in week-old rats using the retrograde tracer Fluorogold (data not shown).

In previous studies when recording from such structures as hippocampus, thalamus, and motor cortex (Mohns and Blumberg, 2010; Tiriac et al., 2012, 2014), we routinely failed to observe substantial neural activity in association with wake-related movements. In contrast, and as expected given the RN's established role in motor behavior, we observed high levels of neural activity during wakefulness (Fig. 2B). We also found a subset of $\mathrm{RN}$ neurons exhibiting substantial wake-related reafferent activity (Fig. 4), a pattern that we have not previously documented. This last finding suggests that corollary discharge mechanisms do not gate or cancel wake-related reafference to the $\mathrm{RN}$, as they appear to do in structures that we have previously investigated (Tiriac et al., 2014).

\section{Anatomical considerations}

Despite the well established anatomical distinction between magnocellular $(\mathrm{RNm})$ and parvocellular $(\mathrm{RNp})$ aspects of the $\mathrm{RN}$ in such species as cats, monkeys, and humans (Kuypers, 1981), the boundaries between them are unclear in the rat (Keifer and Lustig, 2000). Our histological data indicate that we recorded from anterior and posterior aspects of the RN, which are associated with the RNp and $\mathrm{RNm}$, respectively. If so, then it may be that cells in both divisions drive motor-related signals to the spinal cord in infant rats, as suggested in adult cats (Pong et al., 2002). Although the contribution of the RNp to motor control has been controversial (Kennedy and Humphrey, 1987), recent 
findings in adult rats support a role for the RNp in the production of skilled reaching (Morris et al., 2015).

\section{Twitch-related activity in the RN as a framework for developmental investigations of sensorimotor integration} Although the RN has been investigated predominantly with respect to its motor functions (Muir and Whishaw, 2000; HermerVazquez et al., 2004; Williams et al., 2014; Morris et al., 2015), exafferent stimulation of the limbs of adult cats and turtles evokes RN activity in a somatotopic manner (Pompeiano and Brodal, 1957; Eccles et al., 1975; Sarrafizadeh et al., 1996). Here, we demonstrate for the first time that sensory feedback arising from twitches during active sleep also triggers RN activity in a somatotopic manner (Fig. 5). This observation suggests that, early in RN development, sensory feedback from twitching contributes to map formation and/or refinement.

The RN is well integrated with other structures that process sensory and motor information, including the deep cerebellar nuclei (Flumerfelt, 1980; Naus et al., 1985), motor cortex (Giuffrida et al., 1988), somatosensory cortex (Ebrahimi-Gaillard and Roger, 1993), and hippocampus (Dypvik and Bland, 2004). Figure 7 provides a schematic representation of how the $\mathrm{RN}$ forms hierarchically organized sensorimotor loops with these structures (Ahissar and Kleinfeld, 2003). These loops comprise descending (e.g., RST) and ascending (e.g., spinocerebellar pathway) connections. Importantly, the role of the $\mathrm{RN}$ in producing twitches and the substantial convergence of twitch-related feedback to the RN from multiple structures suggests that it is an important site of sensorimotor integration.

Figure 7 also suggests that the $\mathrm{RN}$ is a foundational structure for the development of multiple sensorimotor brain networks. As but one example, activation of the RN in adult rats drives theta oscillations in the hippocampus via the medial septum (Dypvik and Bland, 2004), in support of the sensorimotor integration model of hippocampal function (Bland and Oddie, 2001). Importantly, in infant rats, twitch-related feedback drives hippocampal theta activity as soon as it emerges at P8 (Mohns and Blumberg, 2008) and twitch-related feedback also drives hippocampal activity via the somatosensory cortex (Mohns and Blumberg, 2010). Thus, the production of twitching by the $\mathrm{RN}$ and the processing of twitch-related feedback in the hippocampus and related structures may contribute to the early development of functionally connected neural networks that support such important functions as spatial navigation (Blumberg, 2015).

\section{References}

Ahissar E, Kleinfeld D (2003) Closed-loop neuronal computations: focus on vibrissa somatosensation in rat. Cereb Cortex 13:53-62. CrossRef Medline

Altmann H, ten Bruggencate G, Sonhof U, Steinberg R (1973) Action of $\gamma$-aminobutyric acid and glycine on red nucleus neurons. Pflugers Arch 342:283-288. CrossRef Medline

Amarasingham A, Harrison MT, Hatsopoulos NG, Geman S (2012) Conditional modeling and the jitter method of spike resampling. J Neurophysiol 107:517-531. CrossRef Medline

Appelberg B (1962) The effect of electrical stimulation in nucleus ruber on the response to stretch in primary and secondary muscle spindle merents. Acta Physiol Scand 56:140-151. CrossRef Medline

Berthier NE, Rosenstein MT, Barto AG (2005) Approximate optimal control as a model for motor learning. Psychol Rev 112:329-346. CrossRef Medline

Bland BH, Oddie SD (2001) Theta band oscillation and synchrony in the hippocampal formation and associated structures: the case for its role in sensorimotor integration. Behav Brain Res 127:119-136. CrossRef Medline

Blumberg MS (2015) The developmental origins of spatial navigation: are we headed in the right direction? Trends Neurosci 38:67-68. CrossRef Medline

Blumberg MS, Seelke AMH (2010) The form and function of infant sleep: From muscle to neocortex. In: The Oxford handbook of developmental behavioral neuroscience (Blumberg MS, Freeman JH, Robinson SR, eds), pp 391-423. New York: Oxford UP.

Blumberg MS, Marques HG, Iida F (2013a) Twitching in sensorimotor development from sleeping rats to robots. Curr Biol 23:R532-R537. CrossRef Medline

Blumberg MS, Coleman CM, Gerth AI, McMurray B (2013b) Spatiotemporal structure of REM sleep twitching reveals developmental origins of motor synergies. Curr Biol 23:2100-2109. CrossRef Medline

Blumberg MS, Coleman CM, Sokoloff G, Weiner JA, Fritszch B, McMurray B (2015) Development of twitching in sleeping infant mice depends on sensory experience. Curr Biol 25:656-662. CrossRef Medline

Boissard R, Gervasoni D, Schmidt MH, Barbagli B, Fort P, Luppi PH (2002) The rat ponto-medullary network responsible for paradoxical sleep onset and maintenance: a combined microinjection and functional neuroanatomical study. Eur J Neurosci 16:1959-1973. Medline

Brooks PL, Peever JH (2012) Identification of the transmitter and receptor mechanisms responsible for REM sleep paralysis. J Neurosci 32:97859795. CrossRef Medline

Chase MH, Morales FR (1990) The atonia and myoclonia of active (REM) sleep. Annu Rev Psychol 41:557-584. Medline

Ciranna L, Licata F, Li Volsi G, Santangelo F (2003) Role of $\mathrm{GABA}_{\mathrm{A}}$ and $\mathrm{GABA}_{\mathrm{B}}$ receptors in GABA-induced inhibition of rat red nucleus neurons. Neurosci Lett 341:221-224. Medline

Cohen J (1988) Statistical power analysis for the behavioral sciences, 2nd ed. Hillsdale, NJ: Erlbaum.

Dypvik AT, Bland BH (2004) Functional connectivity between the red nucleus and the hippocampus supports the role of hippocampal formation in sensorimotor integration. J Neurophysiol 92:2040-2050. CrossRef Medline

Ebrahimi-Gaillard A, Roger M (1993) The corticorubral projection in rats: topographic distribution of fibers arising from areas of the sensorimotor cortex functionally identified by microstimulation (in French). C R Acad Sci III 316:502-507. Medline

Eccles JC, Rantucci T, Scheid P, Táboníková H (1975) Somatotopic studies on red nucleus: spinal projection level and respective receptive fields. J Neurophysiol 38:965-980. Medline

Flumerfelt BA (1980) An ultrastructural investigation of afferent connections of the red nucleus in the rat. J Anat 131:621-633. Medline

Gassel MM, Marchiafava PL, Pompeiano O (1966) Rubrospinal influences during desynchronized sleep. Nature 209:1218-1220. CrossRef Medline

Giuffrida R, Li Volsi G, Perciavalle V (1988) Influences of cerebral cortex and cerebellum on the red nucleus of the rat. Behav Brain Res 28:109-111. CrossRef Medline

Harrison MT, Geman S (2009) A rate and history-preserving resampling algorithm for neural spike trains. Neural Comput 21:1244-1258. CrossRef Medline

Hermer-Vazquez L, Hermer-Vazquez R, Moxon KA, Kuo KH, Viau V, Zhan Y, Chapin JK (2004) Distinct temporal activity patterns in the rat M1 and red nucleus during skilled versus unskilled limb movement. Behav Brain Res 150:93-107. CrossRef Medline

Holstege G, Tan J (1988) Projections from the red nucleus and surrounding areas to the brainstem and spinal cord in the cat. An HRP and autoradiographical tracing study. Behav Brain Res 28:33-57. CrossRef Medline

Jiang MC, Alheid GF, Nunzi MG, Houk JC, Houk JC (2002) Cerebellar input to magnocellular neurons in the red nucleus of the mouse: synaptic analysis in horizontal brain slices incorporating cerebello-rubral pathways. Neuroscience 110:105-121. CrossRef Medline

Jouvet-Mounier D, Astic L, Lacote D (1970) Ontogenesis of the states of sleep in rat, cat, and guinea pig during the first postnatal month. Dev Psychobiol 2:216-239. Medline

Karlsson KA, Blumberg MS (2005) Active medullary control of atonia in week-old rats. Neuroscience 130:275-283. CrossRef Medline

Karlsson KA, Gall AJ, Mohns EJ, Seelke AM, Blumberg MS (2005) The neural substrates of infant sleep in rats. PLoS Biol 3:e143. Medline

Keifer J, Lustig DG (2000) Comparison of cortically and subcortically controlled motor systems. II. Distribution of anterogradely labeled terminal boutons on intracellularly filled rubrospinal neurons in the rat. J Comp Neurol 416:101-111. CrossRef Medline 
Kennedy PR, Humphrey DR (1987) The compensatory role of the parvocellular division of the red nucleus in operantly conditioned rats. Neurosci Res 5:39-62. CrossRef Medline

Khazipov R, Sirota A, Leinekugel X, Holmes GL, Ben-Ari Y, Buzsáki G (2004) Early motor activity drives spindle bursts in the developing somatosensory cortex. Nature 432:758-761. CrossRef Medline

Kreider JC, Blumberg MS (2000) Mesopontine contribution to the expression of active "twitch" sleep in decerebrate week-old rats. Brain Res 872: 149-159. CrossRef Medline

Kuypers HG (1981) Anatomy of the descending pathways. In: Handbook of physiology, neurophysiology, vol II (Brookhart JM, Mountcastle VB, eds), pp 597-666. Bethesda, MD: American Physiological Society.

Leonard CS, Llinás R (1994) Serotonergic and cholinergic inhibition of mesopontine cholinergic neurons controlling REM sleep: an in vitro electrophysiological study. Neuroscience 59:309-330. CrossRef Medline

Li D, Peever JH (2014) Pharmacogenetic stimulation of the red nucleus influences muscle tone during rapid eye movement (REM) sleep in mice. Conference presented at the Annual Meeting of the Associated Professional Sleep Societies, SLEEP, Minneapolis, MN, July.

Lisman JE (1997) Bursts as a unit of neural information: making unreliable synapses reliable. Trends Neurosci 20:38-43. CrossRef Medline

Mileykovskiy BY, Kiyashchenko LI, Siegel JM (2002) Cessation of activity in red nucleus neurons during stimulation of the medial medulla in decerebrate rats. J Physiol 545:997-1006. CrossRef Medline

Mohns EJ, Blumberg MS (2008) Synchronous bursts of neuronal activity in the developing hippocampus: modulation by active sleep and association with emerging gamma and theta rhythms. J Neurosci 28:10134-10144. CrossRef Medline

Mohns EJ, Blumberg MS (2010) Neocortical activation of the hippocampus during sleep in newborn rats. J Neurosci 30:3438-3449. CrossRef Medline

Morris R, Vallester KK, Newton SS, Kearsley AP, Whishaw IQ (2015) The differential contributions of the parvocellular and the magnocellular subdivisions of the red nucleus to skilled reaching in the rat. Neuroscience 295:48-57. CrossRef Medline

Muir GD, Whishaw IQ (2000) Red nucleus lesions impair overground locomotion in rats: a kinetic analysis. Eur J Neurosci 12:1113-1122. CrossRef Medline

Naus CG, Flumerfelt BA, Hrycyshyn AW (1985) An HRP-TMB ultrastructural study of rubral afferents in the rat. J Comp Neurol 239:453-465. CrossRef Medline

Padel Y, Bourbonnais D (1985) A ventral spinal pathway transmitting sensory input to rubrospinal cells in the cat. Neurosci Lett Suppl 22:S8.

Padel Y, Jeneskog T (1981) Inhibition of rubro/spinal cells by somaesthetic afferent activity. Neurosci Lett 21:177-182. CrossRef Medline

Padel Y, Sybirska E, Bourbonnais D, Vinay L (1988) Electrophysiological identification of a somaesthetic pathway to the red nucleus. Behav Brain Res 28:139-151. CrossRef Medline

Peever J, Luppi PH, Montplaisir J (2014) Breakdown in REM sleep circuitry underlies REM sleep behavior disorder. Trends Neurosci 37:279-288. CrossRef Medline

Petersson P, Waldenström A, Fåhraeus C, Schouenborg J (2003) Spontaneous muscle twitches during sleep guide spinal self-organization. Nature 424:72-75. CrossRef Medline

Pompeiano O, Brodal A (1957) Experimental demonstration of a somatotopical origin of rubrospinal fibers in the cat. J Comp Neurol 108:225251. CrossRef Medline

Pong M, Horn KM, Gibson AR (2002) Spinal projections of the cat parvocellular red nucleus. J Neurophysiol 87:453-468. Medline

Robinson SR, Blumberg MS, Lane MS, Kreber LA (2000) Spontaneous motor activity in fetal and infant rats is organized into discrete multilimb bouts. Behav Neurosci 114:328-336. CrossRef Medline

Robinson SR, Kleven GA, Brumley MR (2008) Prenatal development of interlimb motor learning in the rat fetus. Infancy 13:204-228. CrossRef Medline

Roffwarg HP, Muzio JN, Dement WC (1966) Ontogenetic development of the human sleep-dream cycle. Science 152:604-619. CrossRef Medline

Sarrafizadeh R, Keifer J, Houk JC (1996) Somatosensory and movementrelated properties of red nucleus: a single unit study in the turtle. Exp Brain Res 108:1-17. Medline

Sato K, Zhang JH, Saika T, Sato M, Tada K, Tohyama M (1991) Localization of glycine receptor alpha 1 subunit mRNA-containing neurons in the rat brain: an analysis using in situ hybridization histochemistry. Neuroscience 43:381-395. CrossRef Medline

Seelke AM, Blumberg MS (2008) The microstructure of active and quiet sleep as cortical delta activity emerges in infant rats. Sleep 31:691-699. Medline

Siegel JM, Nienhuis R, Fahringer HM, Chiu C, Dement WC, Mignot E, Lufkin R (1992) Activity of medial mesopontine units during cataplexy and sleep-walking states in the narcoleptic dog. J Neurosci 12:1640-1646. Medline

Sokoloff G, Uitermarkt BD, Blumberg MS (2014) REM sleep twitches rouse nascent cerebellar circuits: implications for sensorimotor development. Dev Neurobiol. Advance online publication. Retrieved April 28, 2015. CrossRef Medline

Stecina K, Slawinska U, Jankowska E (2008) Ipsilateral actions from the feline red nucleus on hindlimb motoneurones. J Physiol 586:5865-5884. CrossRef Medline

Tiriac A, Uitermarkt BD, Fanning AS, Sokoloff G, Blumberg MS (2012) Rapid whisker movements in sleep newborn rats. Curr Biol 22:20752080. CrossRef Medline

Tiriac A, Del Rio-Bermudez C, Blumberg MS (2014) Self-generated movements with "unexpected" sensory consequences. Curr Biol 24:21362141. CrossRef Medline

Williams PT, Kim S, Martin JH (2014) Postnatal maturation of the red nucleus motor map depends on rubrospinal connections with forelimb motor pools. J Neurosci 34:4432-4441. CrossRef Medline

Wolpert DM, Ghahramani Z, Jordan MI (1995) An internal model for sensorimotor integration. Science 269:1880-1882. CrossRef Medline 